\title{
Research on the Consultative Democracy Practice Model from the Perspective of Internet Politics
}

\author{
Shuyan Liư ${ }^{1, a}$
}

1 Party School of the Shandong Provincial Committee of the CPC, Jinan, Shandong, China, 250103

aemail,

\author{
Keywords: Internet Politics, Negotiation Democracy, Practice Mode
}

\begin{abstract}
In recent years, the field of technology in the world is ushering in the "big data", "crowd-sourcing" as the core of the emerging network of technological revolution, and political areas, especially in the democratization of democracy as the representative of the democratization process has also been promoted. In the pace of development and construction in China, these two forces are the powerful forces that can change the face of our country. But for now, how to combine these two forces into the organic integration, to become a change in Chinese modern governance capacity of the powerful or academic research focus. Based on the current situation of our country, this paper starts from the perspective of Internet politics and explores how to integrate the practice mode of consultation democracy in political theory.
\end{abstract}

\section{Introduction}

In the present era, with a new round of information technology as the core of a new round of scientific and technological revolution is emerging, the rapid development of Internet technology, making it increasingly innovation-driven development of the pilot force for people's production and life is a profound change, for social development have a strong role in promoting [1]. In this context, there is a need to pay attention to the phenomenon that the number of mobile media surge, such as the number of mobile phone users in this stage has been a surge. Traditional interpersonal communication, organizational communication and mass communication are under the support of Internet technology to achieve a comprehensive docking, the global community has also entered the "national microphone era." In this era, people's life production activities have undergone great changes and the pattern of public opinion in society at this stage there have been continuous impact, and even the impact on the political agenda [2]. Micro-blogging, We-Chat and other mobile technology development will also have a profound impact on the process of political development, driven by these social media, individuals in the consumption and the creation of public affairs information, which can be a strong information dissemination and political operational force to inherit. It can be said that the political agenda of the world today is being rewritten by the dual power of WEB2.0. The rapid development of Internet technology at this stage, in the way of communication between people and the reconstruction of social information dissemination at the same time, but also the picture of people's political life had a profound impact, and thus make the political theory of research new problems, open new research areas. It is in this context that Internet politics as a new cross-disciplinary discipline begins to enter into the scope of scholarly research. In recent years, with the electronic democracy and electronic mobilization and other theories put forward and development, Internet politics also began to attract foreign scholars generally concerned.

\section{The Significance Analysis of Consultative Democracy Practice Model from the Perspective of Internet Politics}

The Theoretical Significance. The division of political knowledge in the sense of normative structure can be divided into three spaces with different degrees, namely, theoretical space, empirical space and technical space [3]. There are still many scholars who focus on the study of 
democratic research in theoretical space, but there are still few scholars who specialize in the study of consultation and democracy. The relevant research in this field also appears. In the three-dimensional space possessed by the Institute of Political Science, theoretical research and the imbalance between empirical research and technical research will be directly reflected in the daily discussion process of deliberative democracy. At this level, it is of great significance to explore the mode of consultation and democracy which is suitable for Chinese national conditions from the perspective of technical space, which is of great significance to promote the further development of Chinese consultation and democracy [4]. There is no doubt that today's Internet space is undergoing vigorous development, social media and large data and other new network technology for the transformation of Chinese new political concept has been shaped, in this environment, the community emerged a network of political expression, Network political participation and the network of emotional catharsis and so on new phenomena, for the social and national construction mode of interaction between the ongoing reconstruction, but also makes our political research field from the reality to the virtual, and then make our democratic political research also appears New material. However, although from the current point of view, domestic and foreign academic research Internet politics is ongoing fermentation and the emergence of temperature trends, but many researchers on the Internet political science is also more vague understanding of the existing results of the study is not difficult to develop, the academic community for the study of Internet politics still remain at the normative level and the value level, or a simple transplant of Western theory, even if some issues related to the reality level, it is difficult to conduct in-depth analysis [4].

The Practical Significance. In the Third Plenary Session of the 18th CPC Central Committee, the CPC Central Committee put forward that we should pay more attention to the soundness of democratic system and enrich the form of democracy, expand the orderly political participation of citizens from various fields and give full play to the superiority of our socialist system Play. Institutionalization is bound to require procedural and technical requirements, which also put forward to strengthen the exploration of democracy has become the focus of today's work [5]. How to strengthen the system construction and realize the socialization of social governance and the standardization has become the main goal of the party and the government's political development in the present and the long term, in the case of the comprehensive improvement of the governance system and the governance ability. Therefore, the strengthening of modern political technology, including consultation and democracy, has become the main task of modern political research. In the development of consultation democracy in China, there is a serious disagreement between theorists and policymakers. Although the theoretical concept is endless, most of them are too vague, and it is difficult to achieve practical effect when dealing with practical problems. On the other hand, although the practice of negotiating democracy is of universal significance, the meaning is very limited. Therefore, the study of democracy in China today depends on the theory feasible and technically feasible. In addition, the practice of the Internet in China has been more than 20 years, standing on the reality of the development point of view, the overall operation of the Internet in China is good, all levels of government for the development of the Internet to pay attention to the degree of continuous improvement, many government websites, Government micro-blogging We-Chat constant competition. Nowadays, Chinese cyberspace is also diversified and diversified, and the channels and methods of government participation in politics are becoming more and more abundant [6]. The development of modern information technology makes decentralization effect, in the country's own society to create a new infrastructure at the same time, will also be on the country and the community to remodel. Although this argument is somewhat justified, it should also be recognized that the freedom in the online world is not exactly equal to the freedom in the real world. The reality of democracy in the network world and the real world in the real world cannot complete equal sign. To the network technology to the role of democracy really play, but also need to start from the practical level, the development of Chinese national conditions and feasible network of democratic practice. 


\section{The Technical Support of the Network Negotiate Democracy}

In the Internet at the visual point of view to carry out the practice of deliberative democracy to explore the network of democratic negotiations is bound to need a strong network technology as a support [7]. Since 2013, Chinese Internet technology in the field met two new phenomena, that is, large data and crowd-sourcing. The arrival of large data for the network technology to provide new opportunities for development, crowd-sourcing has begun to become a network technology and application development driven new impetus.

Large Data. Beginning in 2008, the United States, "Nature" magazine for the first time put forward the concept of big data, that is, large data. Followed by many foreign institutions have also issued a large data on the research report, officially opened the "big data era" curtain. Large data is the product of the development of information society to a certain stage, the current understanding of large data is still in the initial stage, academia and the industry for the understanding of large data are focused on each other has not yet formed a complete theoretical system, it is difficult its precise definition. Wikipedia on the definition of large data is involved in the amount of data is very large scale, for business decision-making to provide more favorable advice. Large data refers not only to a single technique, but to a specific connotation and a set of techniques. Domestic scholars believe that large data is through the analysis of massive data, through the access to products with great value and services, and ultimately to form a strong force of change [8]. Big data is just the time in the IT industry, but as a new technology, it is then introduced into social governance and related areas of social administration.

Crowd-sourcing. The crowd-sourcing was presented by American scholars in 2006, which refers to assignments to designated objects in accordance with traditional practices and now allocate them to more and uncertain participants by means of network outsourcing. In layman's terms, this is a business model that should have been completed by the staff of the company to complete the business model, this way and the ancient said "Zhang Bang reward" has the same purpose. In theory, the innovative approach of crowd-sourcing can be regarded as a new attempt of the principal-agent theory. In practice, this approach is mainly an online virtual community composed of contractors, solvers and platforms. The contractor issues a contest task on the platform and submits the appropriate solution. Before the concept of crowd-sourcing, similar practice has been successful in practical business activities [9]. The emergence of crowd-sourcing for the country and the government's policy development also brought new development of myogenic.

\section{The Realization of the Network Negotiate Democracy}

The Main Choice. After World War II, the process of democratization in the world has yielded a general experience that the establishment of a stable democratic model is generally dependent on the strong promotion of the main body and the corresponding promotion of institutions. In the course of the process of democratization in our country, the government has played the main function of promoting the process of democratization. The CPPCC, as its own democratic institution, has promoted the process of democratization in our country. It played an important role to promote Chinese process of consultation and democratic process. Therefore, in the network democracy and the negotiation of democratic docking, we should play the main role of the CPPCC. Specifically, the advantages of the CPPCC in promoting the integration between network democracy and deliberative democracy are reflected in the following aspects: First, the CPPCC has the ability to coordinate. Chinese CPPCC has more than three thousand organizations at all levels, with the main advantages of information through train, all levels of CPPCC have formed a criss-cross the work of the network, the CPPCC and the party and government departments, civil society also established a stable work between Contact [10]. This in the specific work, it can be said that the CPPCC has built a variety of channels of communication. Choose the CPPCC as a platform for the implementation of the carrier and the platform can play a pivotal role. Secondly, the CPPCC has a detached position in society. The CPPCC is neither a state organ nor a general type of social 
organization, and it can be understood as a special organization between state organs and social organizations. Through this form to the development of our people's democracy, on the one hand can capture the greatest essence of people's democracy, on the other hand can also make the national sense of democracy began to return to the social level, for Marx's development of democratic politics have been met.

The Advancing Direction. Network negotiation democracy as a new type of practice program, the most ideal state is in the country to its linkage, and the network to discuss democracy and common progress in China, such a complex internal relations and significant differences in the country, any new The promotion of practical forms need to be gradual. The use of local development drives the overall development, and the theoretical framework to improve, so that practical experience can be accumulated, and then the overall development of the network to promote the promotion of democracy. Therefore, in the face of new development path, also means that the face of the strategy to choose. From the reality of the situation, with the rapid development of Chinese economy, the government functions began to change, Chinese society in the economic structure, employment patterns and the distribution of benefits and other aspects of the increasingly diversified, fine social management. At this time, public affairs and social management functions began to sink to the grassroots level, followed by historical and social contradictions appear downward [11]. For now, the grassroots is becoming a confrontation of various contradictions and conflicts of interest. Therefore, the Internet should be the main stage of deliberative democracy placed at the grassroots level, on the one hand to promote grass-roots government in dealing with various crises and problems with the help of power, so that grass-roots governance capacity has been improved. In addition, the grassroots in the face of many problems, but also for the new model in the grassroots development to provide a wealth of topics, is conducive to the accumulation of new models of operational experience, improve the grassroots development.

\section{Conclusion}

In general, the differences in the development of the network are closely related to the regional economic development. For now, the important trend of network development is the smart carrier as the main carrier of mobile Internet technology. As an important supplement to the traditional representative democracy, the deliberative democracy emphasizes the equal value in the consultation process from beginning to end and attaches importance to the equal ideal dialogue between the subjects and the equal status of the participants in the consultation process.

\section{Acknowledgements}

Fund Project: This paper is the philosophical achievement of the study on the effectiveness of Chinese network democracy in the general project of social science planning in Shandong province (16CDJJ03).

\section{References}

[1] Li Yao Yao, Zhang Xiaobing. Current Western countries to discuss the pattern and practice of democracy [J]. Shanghai People's Monthly, 2015, 08: 53-54.

[2] Zhu Chenchen, Xu Kaiyi. Advocating the grassroots practice of democracy - the "Advisory Committee" model [J / OL]. Theory and reform, 2015 (05). Http: //www.cnki.net/ Kcms / detail / 10.13553 / j.cnki.llygg.2015.05.022.html

[3] Chen Huai-ping. Connotation, subject and scope: combing Chinese theory and practice of consultation and democracy [J]. Journal of Hunan Normal University Social Sciences, 2014,02: 60-65.

[4] Chen Huai-ping. Analysis of Chinese Consultative Democracy Based on Theory and Value Origin - Discussing with Mr. Li Jingzhi [J]. Socialism Research, 2014, 02: 1-7. 
[5] Huang Guohua, Wu Bijun, Wang Xiaoming.Study on Grassroots Consultation Democracy in the View of Socialist Negotiation of Democracy [J]. Journal of Chongqing Institute of Socialism, 2014, 06: 77-85.

[6] Li Wen.Discussion on the Difficulty of Negotiating Democracy[J]. Journal of Tianjin Institute of Socialism, 2015,04: 59-61.

[7] Zhang Dengwen, Yang Caiyi. Study on Chinese grass-roots consultation democracy and its sustainability [J]. Journal of Northeast Normal University (Philosophy and Social Sciences), 2016, 02: 83-88

[8] Shen Jianlin, Tan Shizhan. Participatory budget of China practice, consultation model and its transformation - based on the perspective of consultation democracy [J / OL]. Hubei social science, 2016 (03). Http: //www.cnki.net / Kcms/detail/10.13660/j.cnki.42-1112/c.013525.html

[9] Yang Weimin. From the "Wenling model" to the characteristics of Zhejiang - Zhejiang Province to explore grass-roots level of consultation and practice and enlightenment[J]. Observation and thinking, 2016, 07: 78-84.

[10] Wang Yannan, Song Bo, Du Shiju. Chinese grassroots consensus democracy and the way out[J]. Journal of Shanghai Institute of Socialism, 2011, 01: 40-44

[11] Fan Huixun. Debate on Deliberative Democracy - A Summary of Studies on Foreign Consultative Democracy[J]. Thesis Monthly, 2013,12: 184-188. 